\title{
Simulation of Slightly Degraded Reinforced Concrete Shaft Lining in Thick Topsoil
}

\author{
Haijian XIE, Henglin LV
}

\begin{abstract}
This paper simulates the degradation of a $20 \mathrm{~m}$-tall shaft lining in thick topsoil at the vertical depth of $500 \mathrm{~m}$. The simulation was carried out under the similarity theory. Three reduced scale models were prepared from the original structure. The first model was subjected to circumferential load and then cured naturally, the second model was subjected to circumferential load and then soaked in corrosive solution, and the third model was subjected to circumferential and vertical loads and then soaked in corrosive solution. Without changing the circumferential load, vertical load was applied to the three models until they failed. The three models were found to have similar failure patterns: the uniform cracks first appeared at the top and bottom of the outer lining; the concrete of the inner lining cracked, and the upper part of the shaft lining was crushed, showing a diagonal shear failure. Model 1 had greater cracking load and ultimate load than model 2 and model 3 . This is because the coupling between vertical and circumferential loads induces micro-cracks between the inner and outer linings, and thus accelerates the corrosion of the RC shaft lining in the corrosive solution.
\end{abstract}

Keywords: circumferential load; shaft lining; similarity theory; thick topsoil; vertical strain

\section{INTRODUCTION}

The reinforced concrete $(\mathrm{RC})$ shaft lining in thick topsoil has long been a research hotspot. Targeting Victoria mine, Canada, Fabich et al. [1] introduced the deep shaft lining and its design method in Victoria mine, Canada, and acquired the information on the rock mass of shaft lining according to geological structure and indoor test results. Rama Mohana Rao [2] detailed the limit state method for concrete design of mine shaft lining, established an analytical formula for the lining thickness, and computed the limit depth of the shaft lined with structural concrete. Beus and Chan [3] described the shaft design in Coeur d'Alene, Idaho, and compared the structural features of circular and rectangular shafts. Spagnoli et al. [4] determined the relationship between the key parameters (i.e. cohesion, friction angle and elastic modulus) acting on the shaft lining and the geometric parameters (i.e. depth, radius and lining thickness) of shaft lining. Bruneau et al. [5] studied the effects of faults and mining sequences on the stability of the main shaft, and attributed shaft degradation to the fault intersecting the shaft in two positions. Hachem and Schleiss [6] reviewed the design guidelines for steel-lined pressure tunnels and shafts and the latest calculation methods for uniform load, and briefly introduced a new research project: derive the structural rigidity of steel-lined pressure tunnels and shafts from water hammer acoustic signals.

Many Chinese scholars have also explored the RC shaft lining in thick topsoil. Cui [7], Yang and Fu [8], Lv et al. [9] and Wang and Wen [10] probed deep into thick topsoil, and conducted physical tests and numerical simulations of the frozen wall and shaft lining in topsoil, revealing that lining failures are caused by the vertical additional force of dewatering. Xu [11], Zhou [12], Xu [13], Zhang [14] and Li [15] investigated the sulfate attack on ordinary concrete from different perspectives (e.g. ultrasonic testing, mechanical properties analysis, and micro-measurement), and drew the following conclusions: the load has a certain impact on the sulfate attack rate on ordinary concrete; the sulfate-resistant concrete can resist the sulfate attack. Peng et al. $[16,17]$ studied the surrounding rock of RC shaft lining, and analyzed the rock-lining relationship. The above studies mainly tackle the failure of frozen wall and shaft lining and the degradation of the lining material, failing to consider lining durability.

In this paper, a part of the RC shaft lining in thick topsoil is selected for physical simulation based on similarity theory. The main purpose is to disclose the change law of mechanical properties of the shaft lining in different natural and mechanical environments. The research results lay the basis for preventing the degradation of RC shaft lining.

\section{METHODOLOGY}

\subsection{Modelling Criteria}

Our simulation model was designed based on similarity theory [18]. According to this theory, the model and the selected part of the RC shaft lining (the original structure) must satisfy the following criteria:

(1) The model should be geometrically similar with the original structure.

(2) The processes of the model and the original structure should reflect similar phenomena of the same nature.

(3) The physical parameters of the model should be proportional to the same parameters of the original structure, and the proportionality should be constant.

(4) The model should have similar initial and boundary conditions with the original structure.

Our simulation model is called a similar model, because of its strict similarities to the original structure in geometry, material and mechanics. It is a reduced scale model made of similar material of the research object. A force system like that of the original structure was applied to the model, recreating the actual working conditions of the original structure. The similarities ensure that it is possible to deduce the load performance of the original structure from the simulation results.

\subsubsection{Parameters of the Original Structure}

The simulation model only focuses on a section of the $\mathrm{RC}$ shaft lining. The simulated height is rather small, compared with the total lining height. Hence, the circumferential and vertical loads were assumed as constants, without considering their variations with heights. The parameters of the original structure are listed in Tab. 1 and Tab. 2. 


\subsubsection{Similarity Criteria}

The mechanical performance of shaft lining is mainly affected by the structure, material, geometry, horizontal load and vertical load of the lining. Considering these factors, the research purpose and simulation contents, the parameter equation can be defined as:

$F\left(\begin{array}{l}L, E_{h_{1}}, E_{h_{2}}, \mu_{h_{1}}, \mu_{h_{2}}, \\ \sigma_{h_{1}}, \sigma_{h_{2}}, y, Q_{1}, Q_{2}, p\end{array}\right)=0$

where, $L$ is the length (m); $E_{h_{1}}$ and $E_{h_{2}}$ are the elastic moduli of inner and outer linings materials, respectively $(\mathrm{MPa}) ; \mu_{h_{1}}$ and $\mu_{h_{2}}$ are the Poisson's ratios of inner and outer linings, respectively; $\sigma_{h_{1}}$ and $\sigma_{h_{2}}$ are the concrete strengths of inner and outer linings, respectively $(\mathrm{MPa}) ; y$ is the total vertical displacement of shaft lining (m); $Q_{1}$ and $Q_{2}$ are the total vertical loads of inner and outer linings, respectively $(\mathrm{kN}) ; p$ is the lateral pressure on shaft lining $(\mathrm{MPa})$.

The following similarity criteria can be obtained by dimensional analysis [9]:

Geometric similarity:

$\pi_{1}=y_{1} / L ; \pi_{12}=y_{2} / L$

Mechanical similarity:

$\pi_{2}=E_{h_{1}} / E_{h_{2}}, \pi_{3}=\sigma_{h_{1}} / E_{h_{2}}, \pi_{4}=\sigma_{h_{2}} / E_{h_{2}}, \pi_{5}=p / E_{h_{2}}$, $\pi_{6}=Q_{1} /\left(E_{h_{2}} L\right)^{2}, \pi_{7}=Q_{2} /\left(E_{h_{2}} L\right)^{2}, \pi_{8}=\mu_{h_{1}}$

Constant similarity:

$\pi_{9}=\mu_{m}, \pi_{10}=\mu_{h 1}, \pi_{11}=\mu_{h 2}$

\subsubsection{Modeling Design}

(1) Determination of the reduced scale

The $500 \sim 520 \mathrm{~m}$ part of the shaft lining was taken for physical simulation based on similarity theory. The reduced scale was selected as $C_{l}=20$ according to the workspace of the test facility and the material availability. Hence, the geometric parameters of the model were determined as follows: the outer diameter of the outer lining, $11400 / 20=$ $570 \mathrm{~mm}$; the inner diameter of the inner lining, $355 \mathrm{~mm}$; the diameter at the junction of outer and inner linings, $460 \mathrm{~mm}$; the effective test height, $20 / 20=1 \mathrm{~m}$.

(2) Selection of similar materials

The inner and outer linings of the model were made of the same materials as the target structure, i.e. $C_{E_{h_{1}}}=C_{E_{h_{2}}}$. Thus, the criteria $\pi_{2}, \pi_{8}$ and $\pi_{9}$ were satisfied.

(3) Simulation of initial load and stress
According to criteria $\pi_{6}, \pi_{7}, \pi_{3}, \pi_{4}$ and $\pi_{5}$, it can be seen that $C_{Q_{1}}=C_{Q 2}=C_{l}^{2}=20^{2}$ and $C_{\sigma_{h_{1}}}=C_{\sigma_{h_{2}}}=C_{p}=1$. In the model, the stress on the shaft lining should be the same as that in the original structure. To this end, the vertical loads on the inner and outer linings of the model were set to $1 / 20^{2}$ of those in the original structure, and the lateral force of the model was set to the same level as that of the original structure.

Since the geostatic stress $\sigma_{1}=125 \mathrm{MPa}$, the force to be applied should be:

$P_{1}=\sigma_{1} \cdot A$

where, $A$ is the cross-sectional size of the model $\left(\mathrm{mm}^{2}\right)$.

The circumferential stress can be computed by the heavy-fluid formula [19]:

$$
p=K H
$$

where, $p$ is the lateral pressure of the outer lining (MPa); $K$ is the quasi-gravitational density $\left(\mathrm{MN} / \mathrm{m}^{3}\right) ; H$ is the calculation depth $(\mathrm{m})$.

(4) Deformation similarity

Similarity criterion $\pi_{1}$ shows that $C_{y}=C_{l}=20$, that is, the total displacement of the model should be $1 / 20$ of the original structure. It may take several years or even a decade for the original structure to fail. The loading speed and structural deformation cannot be strictly reflected in our simulation. Hence, the author approximated the actual situation by slowing down the loading speed, and controlling the deformation rate.

According to the above similarity criteria and the modelling design, the simulation parameters were finalized (Tab. 1 - Tab. 2). The longitudinal section and cross-section of the model are illustrated in Fig. 1.
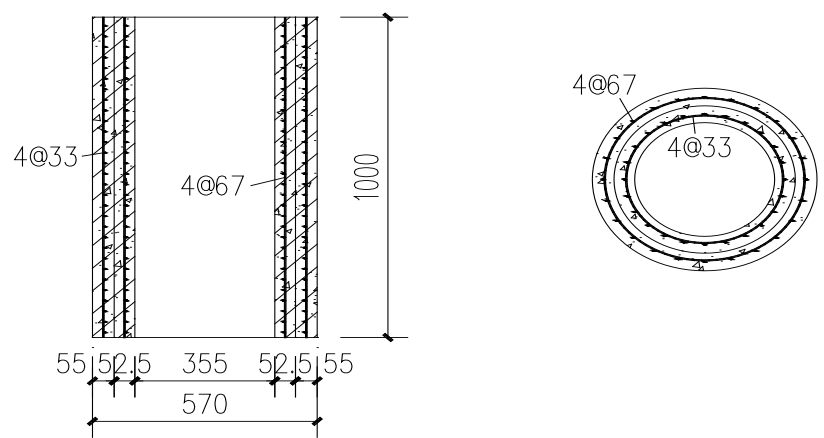

Figure 1 Longtiduinal section and cross-section of the model / $\mathrm{mm}$

Table 1 Geometric sizes of the model

\begin{tabular}{|c|c|c|c|c|}
\hline & $\begin{array}{c}\text { Reduced } \\
\text { scale / } \mathrm{mm}\end{array}$ & $\begin{array}{c}\text { Outer } \\
\text { diameter of } \\
\text { outer lining / } \\
\mathrm{mm}\end{array}$ & $\begin{array}{c}\text { Inner } \\
\text { diameter of } \\
\text { outer lining } \\
/ \mathrm{mm}\end{array}$ & $\begin{array}{c}\text { Inner } \\
\text { diameter of } \\
\text { inner lining } \\
/ \mathrm{mm}\end{array}$ \\
\hline $\begin{array}{c}\text { Original } \\
\text { structure }\end{array}$ & 20 & 11400 & 9200 & 7100 \\
\hline Model & 1 & 570 & 460 & 355 \\
\hline
\end{tabular}

Table 2 Simulation parameters

\begin{tabular}{|c|c|c|c|c|c|}
\hline & \multicolumn{4}{|c|}{ Reinforcement of outer lining / mm } & \multicolumn{2}{c|}{ Reinforcement of inner lining / mm } \\
\cline { 2 - 5 } & Circumferential & Longitudinal & Circumferential & Longitudinal \\
\hline Original structure & $32 @ 200$ & $25 @ 250$ & $32 @ 200$ & $25 @ 250$ & C60 \\
\hline Model & $4 @ 33$ & $4 @ 67$ & $4 @ 33$ & 4967 & C60 \\
\hline
\end{tabular}

Note: $32 @ 200$ means the rebars (diameter:32 mm) are arranged at an interval of $200 \mathrm{~mm}$. 


\subsection{Model Preparation}

Three shaft lining models were prepared with $\mathrm{C} 60$ concrete. The concrete was made from ordinary Portland cement, pebbles, fine sand, silica fume, fly ash and polycarboxylate water reducer. For each model, the outer lining was poured first; after $24 \mathrm{~h}$, the inner formwork was removed; then, an aluminum composite panel was applied; finally, the inner lining was poured.

Three shaft lining models were prepared with C60 concrete. The concrete was made from ordinary Portland cement, pebbles, fine sand, silica fume, fly ash and polycarboxylate water reducer. For each model, the outer lining was poured first; after $24 \mathrm{~h}$, the inner formwork was removed; then, an aluminum composite panel was applied; finally, the inner lining was poured.

\subsection{Test Arrangement and Environment Setting}

Considering research purpose and simulation contents, our simulation was divided into two phases. The first phase is detailed in Tab. 3 below. In the second phase, the circumferential load was kept unchanged, and the three models were applied vertical load until failure.

Table 3 Procedure of the first phase

\begin{tabular}{|c|c|c|c|}
\hline & Quantity / unit & Simulation of natural (or corrosive) environment & Simulation of mechanical environment \\
\hline Model 1 & 1 & Natural curing & Circumferential loading \\
\hline Model 2 & 1 & Phytotron (inner lining) / soaking (outer lining) & Circumferential loading \\
\hline Model 3 & 1 & Phytotron (inner lining) / soaking (outer lining) & Vertical loading and circumferential loading \\
\hline
\end{tabular}

The inner and outer linings are in different environments [20]. These environments of first phase were simulated for our models in the following steps:

Step 1. To simulate the horizontal pressure from soil and water, prestressed steel strands were adopted to apply circumferential load to the outer lining of model 1 , model 2 and model 3.

Step 2. To simulate the top-down dead load of the shaft lining, vertical jacks were employed to apply vertical loads on inner and outer linings of model 3.
Step 3. To simulate the erosion of the inner lining under combined effects of gas, liquid, solid, temperature and humidity (Tab. 4), model 2 and model 3 were entirely placed in aphytotron. Model 1 (comparison object) was placed in natural environment.

Step 4. To simulate the erosion of the outer lining by corrosive media, the outer lining of model 2 and model 3 were surrounded by a ring of steel plates, and the gap between the outer lining and the steel plates was injected with corrosive solution (Tab. 4).

The simulation environment is shown in Fig. 2.

Table 4 Parameter settings of the simulation environment

\begin{tabular}{|c|c|c|c|c|c|c|}
\hline & \multicolumn{5}{|c|}{ Environmental settings } & Humidity $/ \%$ \\
\cline { 2 - 6 } & $\mathrm{Gas} / \mathrm{ppm}$ & Acid mist $/ \mathrm{mg} / \mathrm{m}^{3}$ & Salt rain $/ \%$ & Temperature $/{ }^{\circ} \mathrm{C}$ & Test procedure \\
\hline $\begin{array}{c}\text { Internal } \\
\text { environment } \\
\text { (inner lining) }\end{array}$ & $\mathrm{CO}_{2} / 12000$ & $\mathrm{HCl} / 250$ & $\mathrm{Na}_{2} \mathrm{SO}_{4} / 10$ & 40 & $\begin{array}{c}\text { The gas is sprayed once a day, } 2 \mathrm{~h} \text { at a } \\
\text { time. }\end{array}$ \\
\hline $\begin{array}{c}\text { External } \\
\text { environment } \\
\text { (outer lining) }\end{array}$ & - & - & $\mathrm{Na}_{2} \mathrm{SO}_{4} / 15$ & 25 & 100 & $\begin{array}{c}\text { The model is soaked in corrosive } \\
\text { solution }\end{array}$ \\
\hline
\end{tabular}

\subsection{Simulation Device and Measurement Method}

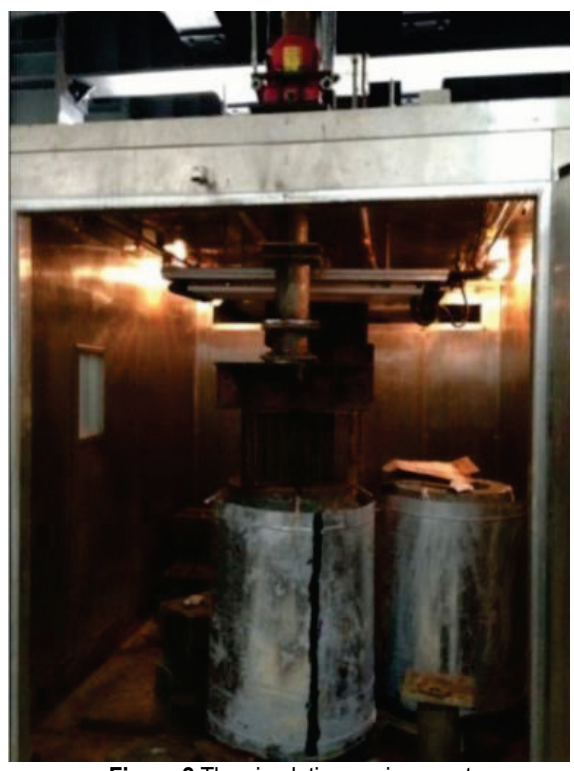

Figure 2 The simulation environment
Our simulation was performed on a large hydraulic compressor with a vertical loading capacity of $7000 \mathrm{kN}$. The upper and lower loading plates are both $600 \times 600 \mathrm{~mm}$.

During the simulation, the following parameters were measured: vertical load, strain at each measuring point, lateral and vertical displacements of shaft lining, and the simulation time. The vertical load was measured by load transducers, the strains were collected by the DH3816 static strain testing system, and the displacements were recorded by displacement meters.

\section{SIMULATION RESULTS AND DISCUSSION \\ 3.1 Phenomena and Failure Features}

The phenomena and failure features of the three models were described below.

(1) Model 1

Before the simulation under vertical load, model 1 was applied a circumferential load and cured naturally for $90 \mathrm{~d}$. The crack propagation and failure of this model are shown in Fig. 3. 
The failure of this model carries obvious features of brittle failure: the middle of the shaft lining was broken first; then, penetrating cracks appeared on the outer lining, while the upper part was crushed. Under the cracking load, cracking sounds were heard clearly from the concrete. New cracks were observed under further loading. Because the inner lining was not observable, our analysis mainly focuses on the crack generation and propagation on the outer lining.

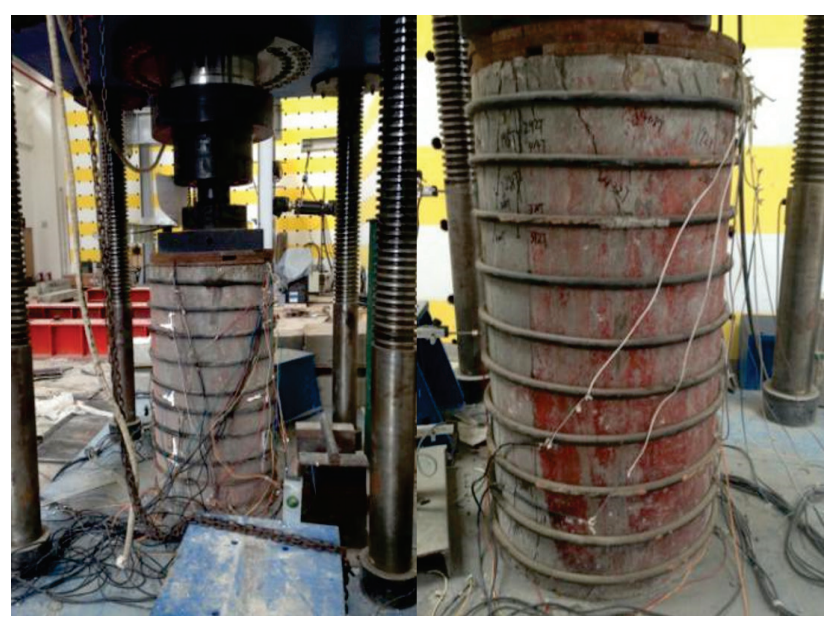

Figure 3 Crack propagation and failure of model 1

Under the initial load, short cracks $(14 \mathrm{~cm})$ emerged in the upper and lower parts of the outer lining due to stress concentration. The cracks were uniformly distributed along the shaft circumference. As the load continued to increase, the concrete started to crack, giving off continuous sounds, and several cracks propagated towards the middle part. Once the load reached $85 \%$ of the ultimate load, cracking sounds were heard continuously from the inner lining, and penetrating cracks were observed on the outer lining. When the load increased to the ultimate load, the upper part of the lining was crushed, showing a diagonal shear failure.

(2) Model 2

Before the simulation under vertical load, model 2 was applied a circumferential load and was placed in phytotron / soaking environment. The crack propagation and failure of this model are shown in Fig. 4.

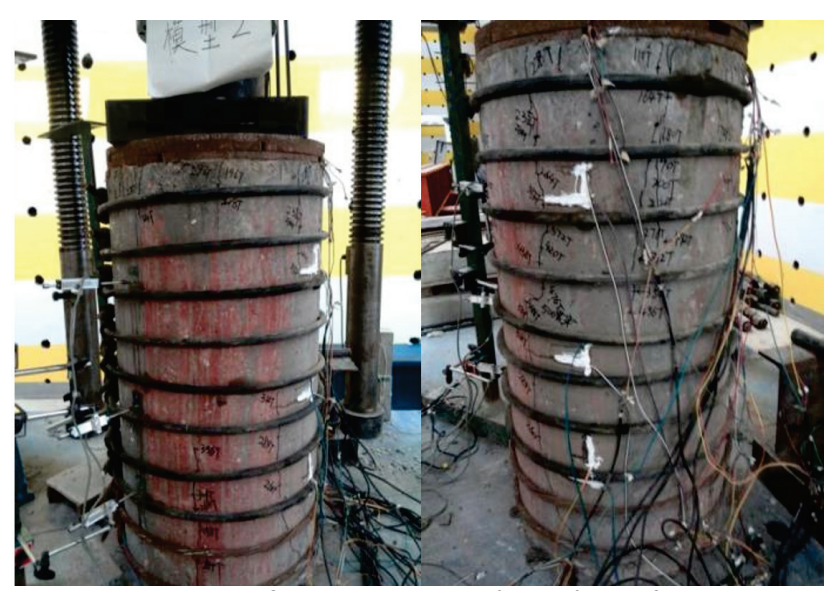

Figure 4 Crack propagation and failure of model 2

The failure of this model also carries obvious features of brittle failure: the outer lining was penetrated by cracks, and the upper part was crushed. Cracking sounds were heard clearly from the concrete when the load reached the cracking load. New cracks were observed under further loading. Below is an analysis on the crack generation and propagation of the outer lining.

Under the initial load, several cracks $(18 \mathrm{~cm})$ were generated in the upper and lower parts of the outer lining, and distributed uniformly along the shaft circumference. Under further loading, cracking sounds were heard, and several cracks propagated towards the middle part. Once the load reached $85 \%$ of the ultimate load, cracking sounds were heard continuously from the inner lining, and penetrating cracks were observed on the outer lining. When the load reached the ultimate load, the upper part of the lining was crushed, showing a diagonal shear failure.

(3) Model 3

Before the simulation under vertical load, model 3 was applied a vertical load and a circumferential load, and was placed in phytotron / soaking environment. The crack propagation and failure of this model are shown in Fig. 5.

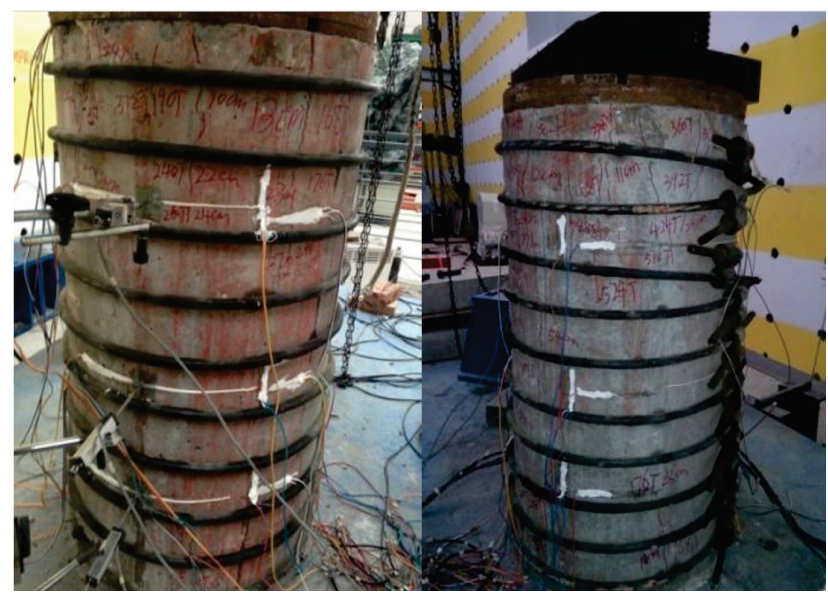

Figure 5 Crack propagation and failure of model 3

Like that of model 2 , the failure of model 3 has obvious features of brittle failure: the outer lining was penetrated by cracks, and the upper part was crushed. Below is an analysis on the crack generation and propagation of the outer lining.

Under the initial load, several cracks appeared in the upper and lower parts of the outer lining. These cracks were longer than those of model 2 in the same period, and obey uniform distribution along the shaft circumference. Under further loading, more cracking sounds were heard, and several cracks propagated towards the middle part. Once the load reached $90 \%$ of the ultimate load, cracking sounds were heard continuously from the inner lining, and penetrating cracks were observed on the outer lining. When the load reached the ultimate load, the upper part of the lining was crushed, showing a diagonal shear failure.

To sum up, the three models share three common failure features:

(1) The cracks first appeared on the top and bottom of the outer lining;

(2) The diagonal cracks coalesced on the outer lining before the failure of the shaft lining.

(3) The concrete of the inner lining was cracked, and the upper part of the shaft lining was crushed, showing a diagonal shear failure. 


\subsection{Ultimate Load of RC Shaft Lining}

The cracking loads and ultimate loads of the three models were obtained (Tab. 5) from the load-displacement relationship and the crack propagation.

Table 5. Mechanical performance of RC shaft lining
\begin{tabular}{|c|c|c|}
\hline & Cracking load / kN & Ultimate load / kN \\
\hline Model 1 & 3840 & 6020 \\
\hline Model 2 & 3780 & 5960 \\
\hline Model 3 & 3740 & 5920 \\
\hline
\end{tabular}

As shown in Tab. 5, model 1 had greater cracking load and ultimate load than model 2 and model 3 . This is because the coupling between vertical and circumferential loads induces micro-cracks between the inner and outer linings, and thus accelerates the corrosion of the $\mathrm{RC}$ shaft lining in the corrosive solution.

\subsection{Load-Displacement Relationship}

The load-displacement curves of the three models are displayed in Fig. 6. It can be seen that, except for the initial segment, the load-displacement curves of all models were basically linear before the peak stress, without any obvious yield points.

Model 2 and model 3 had highly similar loaddisplacement curves. Unlike the load-displacement curve of model 1, the load-displacement curves of models 2 and 3 both had a gentle slope at the beginning. This slope is the result of the corrosion of the RC shafting lining between the inner and outer linings. At the initial stage of the simulation, the micro-cracks and defects induced by corrosion are closed, leading to relatively large macroscopic displacement and gentle slope of load-displacement curve.

The three models exhibited basically the same failure mode, with peak displacements at $18,30 \mathrm{~mm} ; 20,95 \mathrm{~mm}$ and $21,95 \mathrm{~mm}$, respectively.

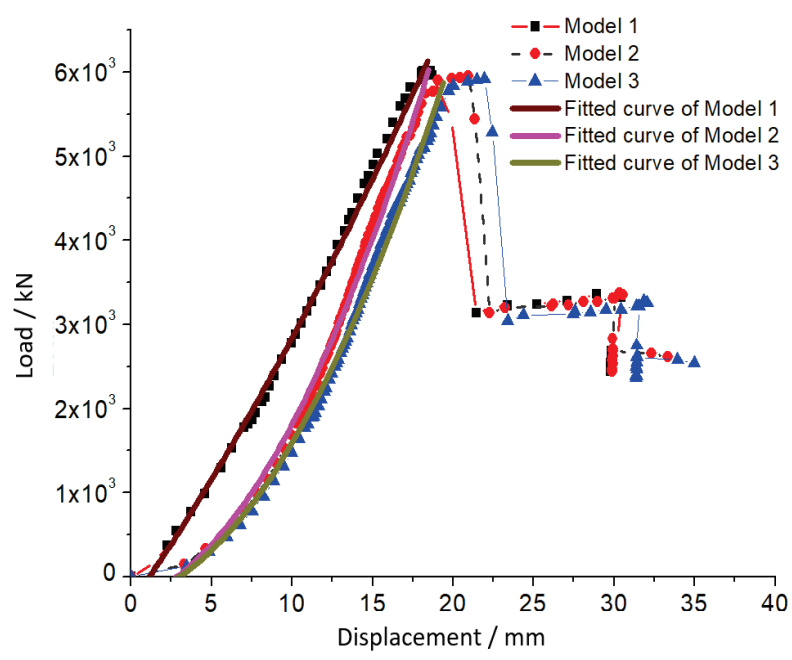

Figure 6 Load-displacement curves of the three models

The curves before the peak load points were regressed, yielding the following formulas:

Model 1:

$y=3,753 x^{2}+281,2 x-339,3 ; R^{2}=0,997$
Model 2:

$y=7,473 x^{2}+210,7 x-871,9 ; R^{2}=0,974$

Model 3:

$y=9,573 x^{2}+134 x-606,7 ; R^{2}=0,972$

\subsection{Load-Strain Relationship 3.4.1 Load-Strain Relationship of Outer Lining}

The load-strain curves of outer lining in the three models are displayed in Fig. 7. It can be seen that, with the growing vertical load, the vertical strain of outer lining in each model showed a linear increase. The vertical strain was not greatly affected by circumferential stress or radial stress. The results agree with the numerical results [12] and the previous studies. In addition, the strain at the height of $50 \mathrm{~cm}$ (i.e. the middle part of the outer lining) was slightly greater than that at the height of $25 \mathrm{~cm}$.

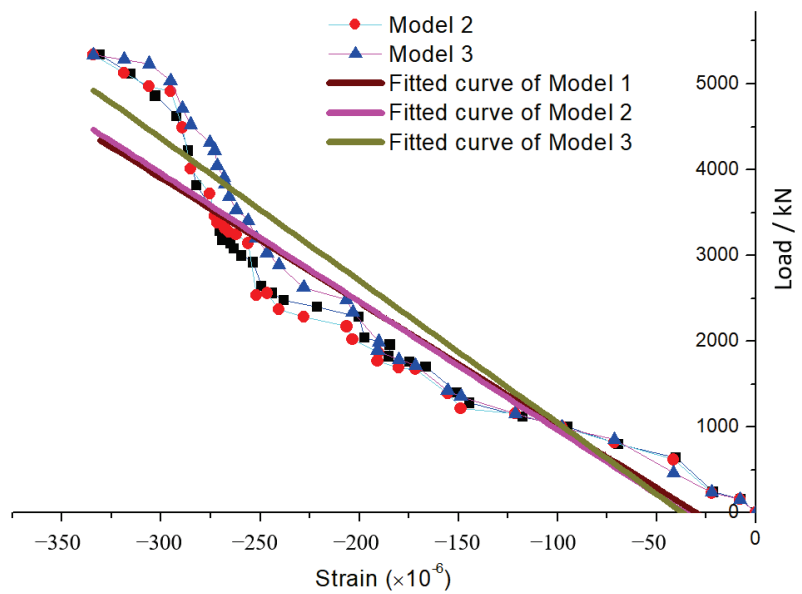

(a) Height: $50 \mathrm{~cm}$

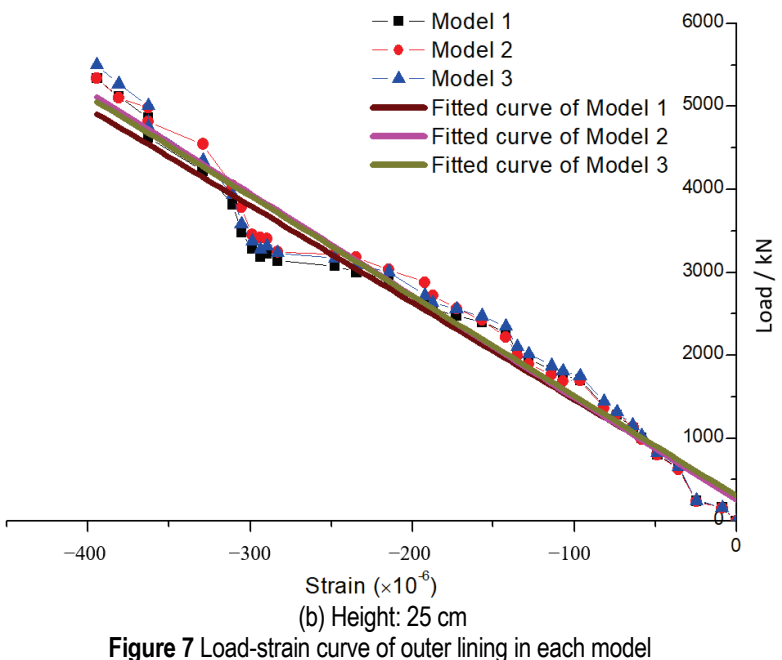

The load-strain curves were linearly regressed, yielding the following formulas:

Model 1:

$y=-14,44 x-433,1 ; R^{2}=0,893($ height: $50 \mathrm{~cm})$ 
$y=-12,21 x+64,51 ; R^{2}=0,958($ height: $25 \mathrm{~cm})$

Model 2:

$$
\begin{aligned}
& y=-14,95 x-530,1 ; R^{2}=0,879(\text { height: } 50 \mathrm{~cm}) \\
& y=-12,58 x-19,24 ; R^{2}=0,978(\text { height: } 25 \mathrm{~cm})
\end{aligned}
$$

Model 3:

$$
\begin{aligned}
& y=-15,90 x-546,9 ; R^{2}=0,929(\text { height: } 50 \mathrm{~cm}) \\
& y=-12,85 x+33,60 ; R^{2}=0,979(\text { height: } 25 \mathrm{~cm})
\end{aligned}
$$

\subsubsection{Load-Strain Relationship of Inner Lining}

The load-strain curves of inner lining in the three models are displayed in Fig. 8. It can be seen that, with the growing vertical load, the vertical strain of inner lining in each model exhibited the same trend as that of outer lining. The vertical strain was still not greatly affected by circumferential stress or radial stress. Moreover, the strain at the height of $50 \mathrm{~cm}$ (i.e. the middle part of the outer lining) was slightly greater than that at the height of $25 \mathrm{~cm}$.

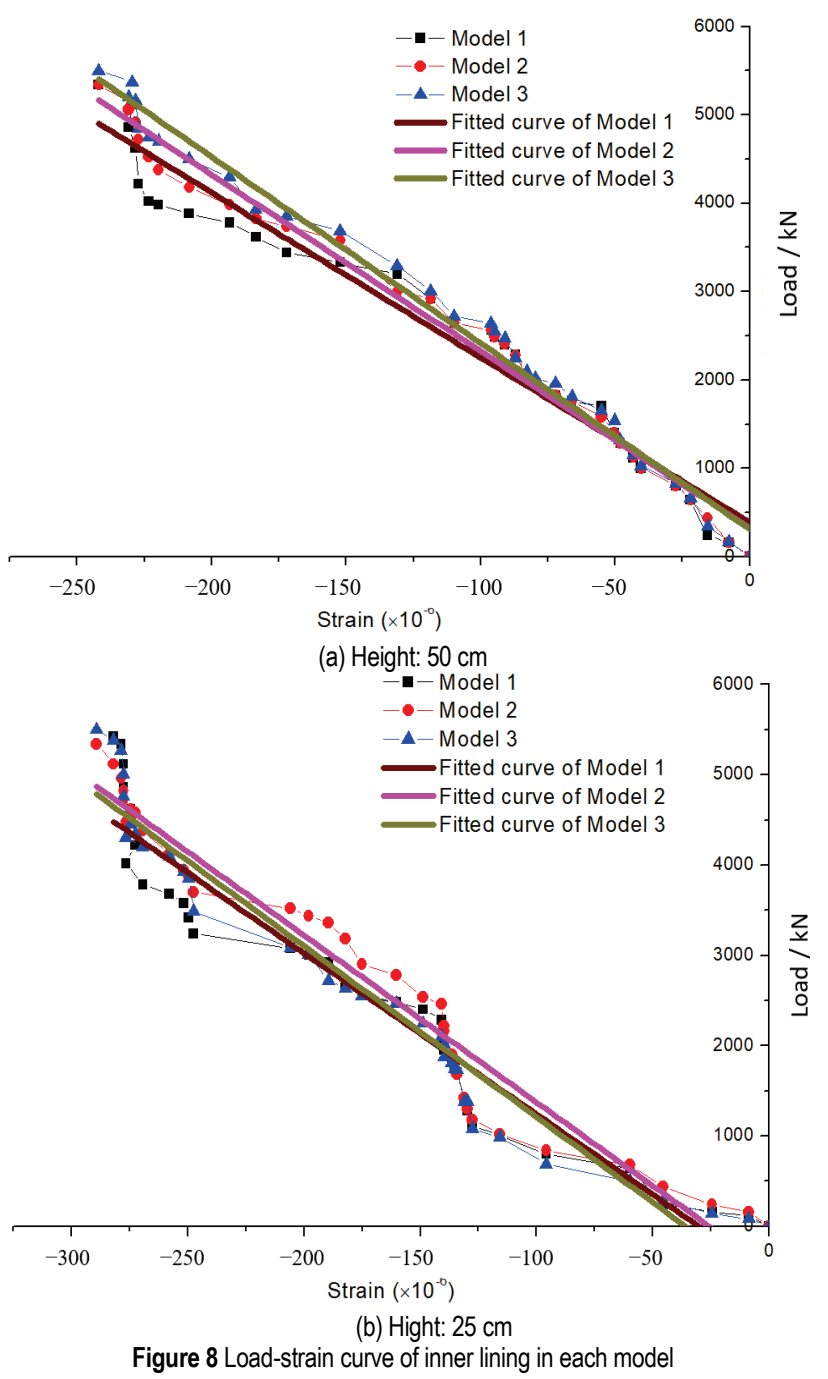

The load-strain curves were linearly regressed, yielding the following formulas:
Model 1:

$y=-18,65 x+387,5 ; R^{2}=0,961$ (height: $\left.50 \mathrm{~cm}\right)$

$y=-16,84 x-433,9 ; R^{2}=0,941$ (height: $\left.25 \mathrm{~cm}\right)$

Model 2:

$y=-20,96 x+291,9 ; R^{2}=0,985($ height: $50 \mathrm{~cm})$

$y=-17,95 x-192,7 ; R^{2}=0,982$ (height: $\left.25 \mathrm{~cm}\right)$

Model 3:

$y=-22,68 x+169,6 ; R^{2}=0,991$ (height: $\left.50 \mathrm{~cm}\right)$

$y=-17,96 x-387,3 ; R^{2}=0,983$ (height: $25 \mathrm{~cm}$ )

\section{CONCLUSIONS}

Considering different natural and mechanical environment of inner and outer linings in RC shaft lining, the degradation of RC shaft lining in thick topsoil was simulated based on similarity theory. The main conclusions are as follows:

(1)The three models had similar failure patterns: the uniform cracks first appeared at the top and bottom of the outer lining; the upper and lower diagonal cracks coalesced on the outer lining before the failure of the shaft lining; the concrete of the inner lining cracked, and the upper part of the shaft lining was crushed, showing a diagonal shear failure.

(2) Model 1 had greater cracking load and ultimate load than model 2 and model 3 . This is because the coupling between vertical and circumferential loads induces microcracks between the inner and outer linings, and thus accelerates the corrosion of the RC shaft lining in the corrosive solution.

(3) The load-displacement curves of the three models are basically quadratic curves, while the load-vertical strain curves of the models are approximated linear curves. The results slightly deviate from the numerical results. The deviation may be attributable to the error in the circumferential loading with prestressed steel strands, and the stress loss of the strands when the loaded model is soaked in corrosive solution.

\section{REFERENCES}

[1] Fabich, S., Bauer, J., Rajczakowska, M., \& Switon, S. P. (2015). Design of the shaft lining and shaft stations for deep polymetallic ore deposits: Victoria mine case study. Mining Science, 22, 127-146. https://doi.org/10.5277/msc152213

[2] Rama Mohana Rao, Y. (1988). Design limit state of structural concrete for mine shaft lining. Indian Concrete Journal, 62(2), 91-96.

[3] Beus, M. J. \& Chan, S. S. M. (1980). A structural approach to shaft design for deep mines in hard rock. 21st U.S. Symposium on Rock Mechanics, USRMS 1980, 780-786.

[4] Spagnoli, G., Oreste, P., \& Bianco, L. L. (2016). New equations for estimating radial loads on deep shaft linings in weak rocks. International Journal of Geomechanics, 16(6). https://doi.org/10.1061/(ASCE)GM.1943-5622.0000657

[5] Bruneau, G., Tyler, D. B., Hadjigeorgiou, J., \& Potvin, Y. (2003). Influence of faulting on a mine shaft-a case study: 
Part I-Background and instrumentation. International Journal of Rock Mechanics and Mining Sciences, 40(1), 95111. https://doi.org/10.1016/S1365-1609(02)00115-6

[6] Hachem, F. E. \& Schleiss, A. J. (2009). The design of steellined pressure tunnels and shafts. International Journal on Hydropower and Dams, 16(3), 142-151.

[7] Cui, G. X. (2000). Progress and Prospects for Special Constructional Technique of Underground Engineering in Complex Stratum. Cement and Concrete Composites, 9(6), 3-8. https://doi.org/10.1016/j.cemconcomp.2014.06.013

[8] Yang, W. H \& Fu, H. L. (1999). Theoretical Investigation on Vertical Additional Force on Shaft Lining in Special Stratum. Journal of China University of Mining \& Technology, 9(2), 129-135.

[9] Lv, H. L., Yang, W. H., \& Zhou, G. Q. (1996). Negative skin friction on bottom-fixed deep pile due to drainage of bottom aquifer. China Civil Engineering Journal, 29(5), 36-42.

[10] Wang, Y. S. \& Wen, K. (2014). Numerical analysis of interaction between freezing wall and shaft lining in deep alluvia. Chinese Journal of Geotechnical Engineering, 36(6), 1142-1146.

[11] Xu, Z. L. (2018). Probe into Shaft Wall Concrete Failure Test in Luohe Ironmine Auxiliary Shaft, Anhui. Coal Geology of China, 29(10), 57-63. https://doi.org/10.3969/.issn.1674-1803.2017.10.10

[12] Zhou, Y. (2017). The Variation of AE Characteristics of Shaft Lining Concrete in Sulfate Corrosion Environment. Beijing University of Science and Technology.

[13] Xu, H. (2012). Research on Damage behavior of concrete under sulfate corrosion. China University of Mining.

[14] Zhang, W. (2015). The effect of shaft concrete in the earlyage under Loads-Chemistry. North China University of Technology.

[15] Li, J. Y. (2012). Sidewall Structure performance degradationmechanism analysis and research of prevention measures. Anhui University of Science and Technology.

[16] Peng, K., Zhou, J. Q., Zou, Q. L., Zhang, J., \& Wu, F. (2019) Effects of stress lower limit during cyclic loading and unloading on deformation characteristics of sandstones. Construction and Building Materials, 217, 202-215. https://doi.org/10.1016/j.conbuildmat.2019.04.183

[17] Peng, K., Wang, Y. Q., Zou, Q. L., Liu, Z. P., \& Mou, J. H. (2019). Effect of crack angles on energy characteristics of sandstones under a complex stress path. Engineering Fracture Mechanics, 218: 106577. https://doi.org/10.1016/j.engfracmech.2019.106577

[18] Lu, H. L. \& Cui, G. X. (2001). Simulation Test Research of Mechanism of Harnessing Shaft Lining Fracture by StressRelief Method. Journal of China University of Mining \& Technology, 30(2), 130-134.

[19] Lu, H. L. \& Cui, G. X. (2001). Study on Numerical Simulation of the Fracture of Single Layer Reinforced Concrete Shaft Lining. Underground Space, 21(5), 399-406.

[20] Xie, H. J. (2016). Study on Degradation Law and Life Prediction of RC Shaft Structure Mechanical Properties in Deep Thick Alluvium Environment. China University of Mining and Technology.

\section{Contact information:}

Haijian XIE, Doctor, Lecturer

School of Naval Architecture and Civil Engineering

Jiangsu University of Science and Technology (Zhangjiagang),

Zhangjiagang City, Jiangsu Province, China

E-mail: Haijianxie@hotmail.com

Henglin LV, Doctor, Professor

(Corresponding author)

School of Mechanics and Civil Engineering,

China University of Mining \& JiangSu Collaborative Innovation Center for

Building Energy Saving and Construction Technology,

Xuzhou City, Jiangsu Province, China

E-mail: Henglinlv@cumt.edu.cn 